\title{
Clinical and prognostic significance of circulating levels of angiopoietin-1 and angiopoietin-2 in hepatocellular carcinoma
}

\author{
Roberto Carmagnani Pestana ${ }^{1}$, Manal M. Hassan'2, Reham Abdel-Wahab ${ }^{3,7}$, Yehia \\ I. Abugabal', Lauren M. Girard ${ }^{3}$, Donghui Li ${ }^{3}$, Ping Chang ${ }^{3}, K_{\text {Kanwal Raghav }}^{3}$, Jeff \\ Morris ${ }^{4}$, Robert A. Wolff ${ }^{3}$, Asif Rashid ${ }^{5}$, Hesham M. Amin ${ }^{6}$ and Ahmed Kaseb ${ }^{3}$ \\ ${ }^{1}$ Department of Cancer Medicine, The University of Texas MD Anderson Cancer Center, Houston, TX, USA \\ ${ }^{2}$ Department of Epidemiology, The University of Texas MD Anderson Cancer Center, Houston, TX, USA \\ ${ }^{3}$ Department of Gastrointestinal Medical Oncology, The University of Texas MD Anderson Cancer Center, Houston, TX, USA \\ ${ }^{4}$ Department of Biostatistics, The University of Texas MD Anderson Cancer Center, Houston, TX, USA \\ ${ }^{5}$ Department of Pathology, The University of Texas MD Anderson Cancer Center, Houston, TX, USA \\ ${ }^{6}$ Department of Hemopathology, The University of Texas MD Anderson Cancer Center, Houston, TX, USA \\ ${ }^{7}$ Department of Clinical Oncology, Assiut University Hospitals, Faculty of Medicine, Assiut, Egypt \\ Correspondence to: Ahmed Kaseb, email: aokaseb@mdanderson.org \\ Manal M. Hassan, email: mhassan@mdanderson.org \\ Keywords: angiogenesis; angiopoietin-1; angiopoietin-2; cirrhosis; hepatocellular carcinoma
}

Abbreviations: Ang-1: angiopoietin-1; Ang-2: angiopoietin-2; HCC: hepatocellular carcinoma; mAB: monoclonal antibody; OS: overall survival

Received: August 08, $2018 \quad$ Accepted: November 16, $2018 \quad$ Published: December 28, 2018

Copyright: Pestana et al. This is an open-access article distributed under the terms of the Creative Commons Attribution License 3.0 (CC BY 3.0), which permits unrestricted use, distribution, and reproduction in any medium, provided the original author and source are credited.

\section{ABSTRACT}

Angiopoietin-1 (Ang-1) and angiopoietin-2 (Ang-2) play critical roles in angiogenesis in hepatocellular carcinoma (HCC). In addition, recent data suggest that Ang-1/Ang-2 are involved in regulating the immune response. The aim of our study was to explore the clinical prognostic significance of plasma Ang-1 and Ang-2 in HCC. We prospectively enrolled and collected data and blood samples from 767 HCC patients treated at MD Anderson Cancer Center between 2001 and 2014. Controls consisted of cirrhotic patients $(n=75)$ and healthy volunteers $(n=200)$. The cutoff value was the median level of each angiogenic factor. Overall survival (OS) was estimated by Kaplan-Meier curves and compared by the log-rank test. Higher plasma Ang-2 was significantly associated with advanced clinicopathologic features of advanced HCC and lower OS. Median OS was 61.8 months (95\% confidence interval [CI], 45.1-78.5 months) for low Ang-2 compared with 28.5 months (95\% CI, 24.8-32.1 months) for high Ang-2 $(p<0.001)$. In contrast, higher Ang-1 was associated with longer $O S$. Median OS was 37.2 months (95\% CI, 31.0-43.4 months) for high Ang-1 compared with 26.2 months (95\% CI, 22.2-30.3 months) for those with low Ang-1 ( $p=0.043)$. In conclusion, our findings indicate that plasma Ang-1 and Ang-2 levels are potential diagnostic and prognostic biomarkers in HCC.

\section{INTRODUCTION}

Hepatocellular carcinoma (HCC), the most common primary liver cancer and the second leading cause of cancer-related death in the world, is responsible for approximately 750,000 deaths per year [1]. Multiple factors are involved in the high mortality rates of $\mathrm{HCC}$, including ineffective screening and lack of access to treatment in some regions [2-4]. In addition, given the asymptomatic nature in its early stages, most HCC cases are detected at an advanced stage, leading to incurable disease states in patients with low hepatic functional reserve [4-6]. The 
development of HCC is closely related to the presence of chronic liver disease, and the most prevalent underlying etiologic factors are viral hepatitis $\mathrm{B}$ and $\mathrm{C}$, exposure to aflatoxins, alcohol use, and nonalcoholic steatohepatitis caused by metabolic syndrome $[7,8]$. Surgical resection, liver transplantation, and radiofrequency ablation are the only curative therapeutic modalities for localized HCC, and treatment options for patients with locally advanced or metastatic disease are limited $[9,10]$.

Sorafenib and lenvatinib, orally available multikinase inhibitors, have demonstrated modest overall survival (OS) benefit and are currently the only systemic therapies approved for first-line treatment of advanced HCC [11, 12]. More recently, immunotherapy was incorporated into the therapeutic arsenal for HCC, as nivolumab was approved in the second-line setting [13]. However, validated predictive and prognostic biomarkers to advance personalized oncologic management, and predict therapeutic outcomes and survival are lacking for this highly aggressive cancer [14].

Notably, HCC development, progression, and metastasis are strongly associated with angiogenesis pathway [11]. Accordingly, antiangiogenic approaches are part of the standard of care in HCC treatment; lenvatinib and sorafenib, for example, target the vascular endothelial growth factor receptor (VEGFR), among other kinases [12]. An imbalance between proangiogenic and antiangiogenic factors is believed to drive angiogenesis in $\operatorname{HCC}[15,16]$. Angiopoietin-1 (Ang-1) and angiopoietin-2 (Ang-2) were first described as ligands for Tie2, a transmembrane receptor tyrosine kinase that regulates survival, proliferation, and migration of endothelial cells [17-19]. In physiologic conditions, homeostatic balance is maintained between Ang-1 and Ang-2 activity [17-19]. Ang-1 is primarily expressed in periendothelial support cells of quiescent blood vessels [11]. Binding of Ang-1 to Tie2 promotes structural integrity of the vascular networks [17-21]. In contrast, Ang-2 is expressed during inflammation-induced vascular remodeling and decreases vascular stabilization [17, 22]. Furthermore, Ang-2 inhibits vascular integrity by competitively inhibiting Ang-1-induced Tie2 activation $[23,24]$. Additional lines of evidence suggest that Ang-2 supports angiogenesis by binding the Tie2 receptor in monocytes [25]. In addition, increasing evidence suggests that Ang-2 promotes recruitment of intratumoral macrophages and promotes PD-L1 expression in M2-polarized macrophages [26].

The intertwined regulation of neoangiogenesis and the immune system can offer therapeutic opportunities, and this is of particular interest since checkpoint inhibitors are incorporated into the treatment of HCC, a highly vascular malignancy [27]. Ang-1 and Ang-2 show promise as prognostic markers for HCC, and a study of plasma biomarkers from the SHARP trial identified circulating Ang-2 levels as the only independent predictor of survival in HCC patients treated with sorafenib or placebo [14, 24]. Similarly, our group reported the predictive significance of Ang-2 in a clinical trial of bevacizumab and erlotinib combination in advanced HCC [28].

The goal of the current study was to determine the prognostic value of plasma levels of Ang-1 and Ang-2 in HCC and to explore the diagnostic utility of plasma Ang-1 and Ang-2 in differentiating cirrhosis from HCC. We examined the prognostic roles of plasma Ang-1 and Ang-2 levels by comparing OS of patients with low versus high plasma Ang-1 and Ang-2 levels to determine whether plasma Ang-1 and Ang-2 were associated with clinicopathologic characteristics.

\section{RESULTS}

Table 1 summarizes the baseline clinical and pathologic characteristics of the $767 \mathrm{HCC}$ patients included in our analysis. Most patients in the study population were older than 60 years $(57.4 \%)$, and the male-to-female ratio was $2.8: 1$. Hepatitis in $65.2 \%$ and alcohol consumption in $73.0 \%$ of patients were the most prevalent risk factors for HCC. Of the 767 HCC patients, 189 (24.6\%) had distant metastasis at initial presentation. Most (76.6\%) had stage C-D of the Barcelona Clinic Liver Cancer (BCLC) HCC classification systems. Comparison between low ( $n=415$ patients) and high ( $n=352$ patients) plasma Ang- 1 levels showed statistically significant differences between the levels based on the presence of cirrhosis, Child-Pugh score, and hepatitis $\mathrm{C}$ virus (HCV) positivity (Figure 1A). Comparison between low ( $n=59$ patients) and high ( $n=708$ patients) plasma Ang-2 levels demonstrated statistically significant differences between the levels based on the presence of cirrhosis, Child-Pugh score, the presence of vascular invasion and vascular thrombosis, tumor involvement $>50 \%$ of the liver, multinodularity, alpha-fetoprotein (AFP) levels, HCV positivity, and history of cigarette smoking (Figure 1B).

Plasma Ang-1 levels were significantly lower in cirrhotic patients $($ mean $=11.6 \mathrm{ng} / \mathrm{ml} ; 95 \% \mathrm{CI}, 10.2-13.0$ $\mathrm{ng} / \mathrm{ml}$ ) than in healthy controls (mean $=16.0 \mathrm{ng} / \mathrm{ml}$; 95\% CI, 14.9-17.1 ng/ml) and in HCC patients (mean $=16.1 \mathrm{ng} / \mathrm{ml} ; 95 \% \mathrm{CI}, 15.4-16.7 \mathrm{ng} / \mathrm{ml})(p<0.001)$ (Figure 2A). In contrast, plasma Ang-2 levels were significantly lower in healthy controls (mean $=4.4 \mathrm{ng} / \mathrm{ml}$; $95 \%$ CI, 4.2-4.7 $\mathrm{ng} / \mathrm{ml})$ than in cirrhotic (mean $=15.2 \mathrm{ng} / \mathrm{ml} ; 95 \% \mathrm{CI}, 12.6-17.8 \mathrm{ng} / \mathrm{ml}$ ) and in HCC patients $($ mean $=15.3 \mathrm{ng} / \mathrm{ml} ; 95 \% \mathrm{CI}, 14.1-16.4 \mathrm{ng} / \mathrm{ml})$ $(p<0.001)$ (Figure 2A). In addition, mean plasma Ang-2 levels were significantly more elevated in HCC patients with a higher Child-Pugh score, higher TNM-stage, HCV positivity, presence of vascular invasion and thrombosis, presence of metastasis, and higher AFP levels, whereas plasma Ang-1 was significantly lower in patients with a more advanced Child-Pugh score and TNM staging (Figure 2A-2H). 
Table 1: Demographic characteristics, risk factors, and clinicopathological characteristics of $767 \mathrm{HCC}$ patients

\begin{tabular}{|c|c|c|}
\hline \multirow[t]{2}{*}{ Variables } & \multicolumn{2}{|c|}{ HCC patients $(n=767)$} \\
\hline & No. of patients & $\%$ \\
\hline \multicolumn{3}{|l|}{ Age at diagnosis (years) } \\
\hline$\leq \mathbf{6 0}$ & 327 & 42.6 \\
\hline$>60$ & 440 & 57.4 \\
\hline \multicolumn{3}{|l|}{ Gender } \\
\hline Male & 567 & 73.9 \\
\hline Female & 200 & 26.1 \\
\hline \multicolumn{3}{|l|}{ Race } \\
\hline White & 514 & 67.0 \\
\hline Non-white & 253 & 33.0 \\
\hline \multicolumn{3}{|l|}{ Hepatitis status } \\
\hline HCV only & 301 & 39.2 \\
\hline HBV only & 88 & 11.5 \\
\hline $\mathrm{HCV}$ and $\mathrm{HBV}$ & 111 & 14.5 \\
\hline History of cigarette smoking & 498 & 64.9 \\
\hline History of alcohol consumption & 560 & 73.0 \\
\hline History of diabetes & 271 & 35.3 \\
\hline AFP level $\geq 20 \mathrm{ng} / \mathrm{dl}$ & 453 & 59.1 \\
\hline AFP level $\geq 400 \mathrm{ng} / \mathrm{dl}$ & 251 & 32.7 \\
\hline Presence of vascular invasion & 241 & 31 \\
\hline Presence of vascular thrombosis & 172 & 22.4 \\
\hline$>\mathbf{5 0} \%$ tumor involvement ${ }^{*}$ & 180 & 23.5 \\
\hline Distant metastasis & 189 & 24.6 \\
\hline Lymph node metastasis & 157 & 20.4 \\
\hline Adjacent organ invasion & 27 & 3.5 \\
\hline Multi-nodularity* & 474 & 61.8 \\
\hline \multicolumn{3}{|l|}{ Tumor differentiation } \\
\hline Well-differentiated & 193 & 25.2 \\
\hline Moderately differentiated & 211 & 27.5 \\
\hline Poorly differentiated & 120 & 13.0 \\
\hline Fibrolamellar & 13 & 1.6 \\
\hline Clear Cell & 7 & 0.9 \\
\hline Presence of cirrhosis & 489 & 63.7 \\
\hline \multicolumn{3}{|l|}{ Child-Pugh class } \\
\hline $\mathbf{A}$ & 412 & 53.7 \\
\hline B & 299 & 39.0 \\
\hline $\mathbf{C}$ & 56 & 7.3 \\
\hline \multicolumn{3}{|l|}{ CLIP staging* } \\
\hline Stage 0-2 & 485 & 63.2 \\
\hline Stage 3-6 & 282 & 36.8 \\
\hline \multicolumn{3}{|l|}{ BCLC staging } \\
\hline Stage 0-B & 172 & 22.4 \\
\hline Stage C-D & 588 & 76.6 \\
\hline
\end{tabular}


TNM staging*

Stage I-II

Stage IIIA-IIIB

Stage IIIC-IVB

Frontline treatment

Surgery or transplant

Local therapy

Finally, our results demonstrated that plasma Ang-1 and Ang-2 levels correlated with OS. Patients with higher plasma Ang-1 levels had significantly better OS than those with low plasma Ang-1 levels. Median OS was 37.2 months (95\% CI, 31.0-43.4 months) for those with high Ang-1 compared with 26.2 months (95\% CI, 22.2-30.3 months) for those with low levels ( $p=0.043$ ) (Figure 3A). Antagonistically, lower plasma Ang-2 levels correlated with prolonged OS. Median OS was 61.8 months (95\% CI, 45.1-78.5 months) for those with low plasma Ang-2 compared with 28.5 months (95\% CI, 24.8-32.1 months) for those with high levels $(p<0.001)$ (Figure 3B).

\section{DISCUSSION}

To the best of our knowledge, we herein describe the largest cohort correlating plasma levels of Ang-1 and Ang-2 with clinical and prognostic characteristics of HCC. Our current study indicates that higher plasma Ang-2 and lower plasma Ang-1 levels are risk factors for shorter OS in HCC. Consistent with our findings, data from clinical trials including our phase II study with bevacizumab and erlotinib [28] in addition to an analysis of plasma biomarkers of patients enrolled in the phase III randomized SHARP trial demonstrated that elevated serum Ang-2 was an independent risk factor for shorter OS in both the sorafenib and the placebo arms [14].

Our results also showed that plasma levels of Ang-1 was significantly lower in cirrhotic patients than in HCC patients and in healthy controls, whereas plasma Ang-2 was significantly more elevated in cirrhotic and HCC patients than in healthy controls. There were no significant differences in Ang-2 levels in cirrhotic vs HCC patients. These findings suggest that Ang-1 and Ang-2 can jointly be explored as noninvasive diagnostic biomarkers of HCC and liver disease. Consistent with our results, a retrospective study by Hernández-Bartolomé et al. [29] analyzing 179 patients had previously demonstrated that although Ang-1 was decreased in cirrhotic compared with non-cirrhotic patients, Ang-2 was significantly increased as the stage of liver disease progressed. Moreover, these authors demonstrated that the ratio of serum Ang2 to Ang-1 displayed notable accuracy $(82.1 \%)$ for the diagnosis of cirrhosis at the optimal cut-off. In contrast to our results, Scholz et al. demonstrated that Ang-2 levels were significantly higher in HCC patients than in cirrhotic patients [30].

Our study demonstrated that higher plasma Ang-2 levels were associated with advanced clinicopathologic features, including higher TNM stage, higher Child-Pugh
A

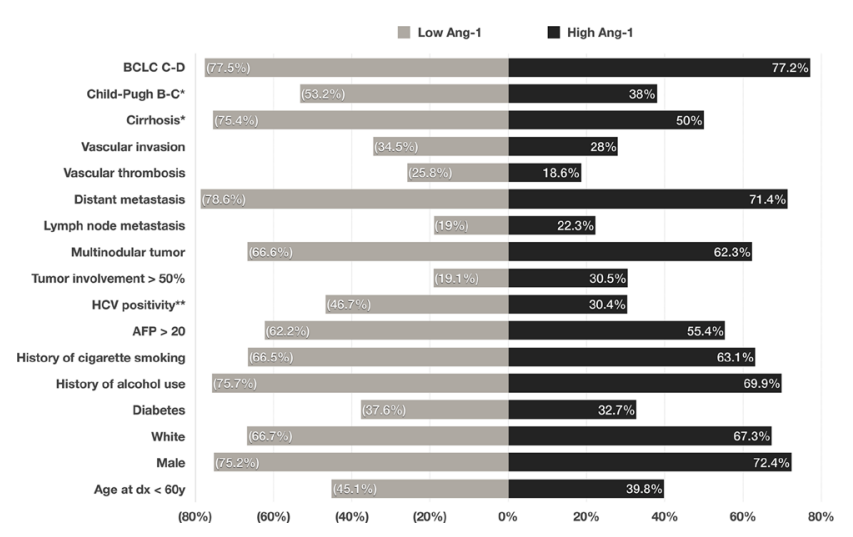

B

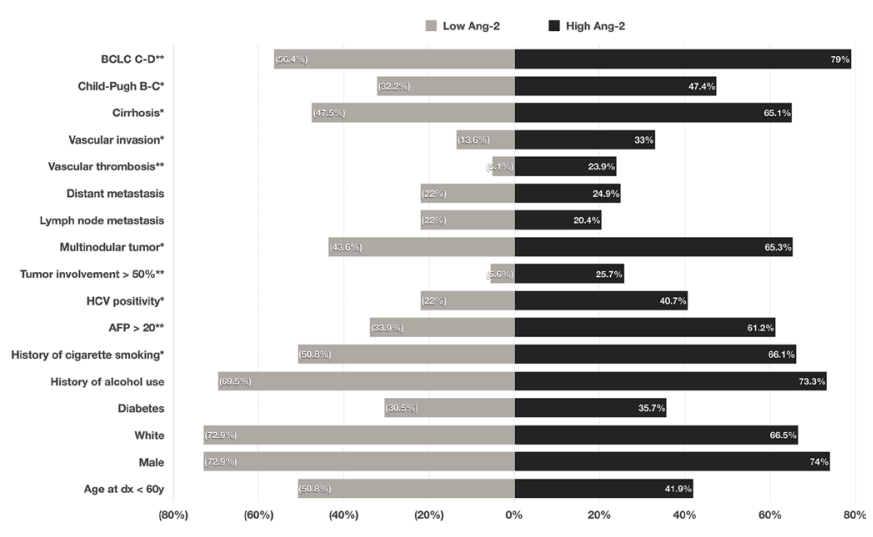

Figure 1: Comparison of prevalence of risk factors, epidemiological parameters, demographic characteristics, and clinicopathological parameters between patients with a low plasma levels of Ang-1 and those with Ang-1 (A); and between those with low plasma levels of Ang-2 and those with high Ang-2 (B). ${ }^{*} p<.05,{ }^{* *} p<.001$. 

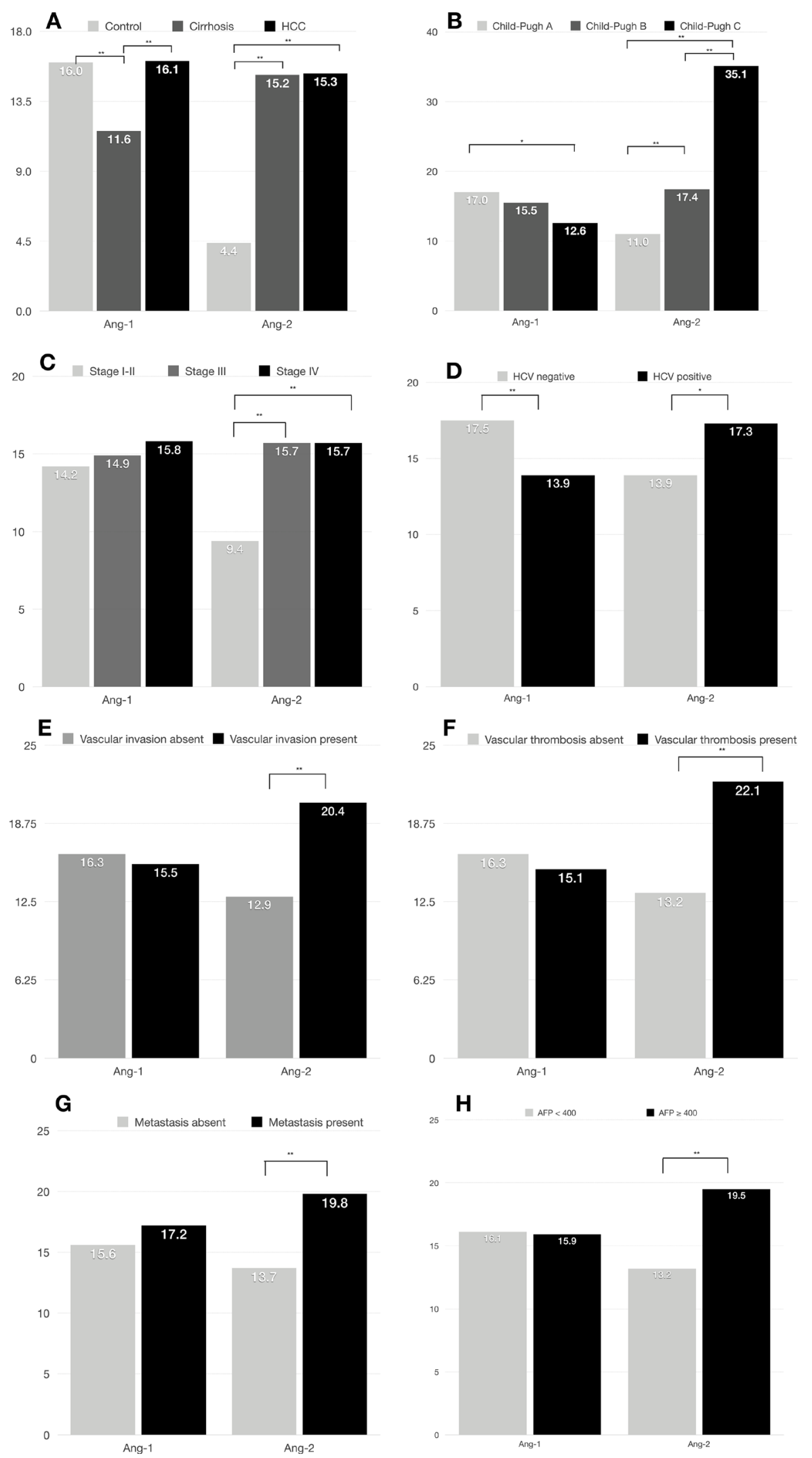

Figure 2: Median plasma Ang-1 and Ang-2 levels by clinical characteristics in 767 HCC patients. (A) Ang-1 and Ang-2 levels correlate with HCC and cirrhosis; (B) Ang-1 and Ang-2 levels correlate with Child-Pugh score; (C) Ang-2 levels correlate with TNM staging; (D) Ang-1 and Ang-2 levels correlate with HCV positivity; (E) Ang-2 levels correlate with vascular invasion; (F) Ang-2 levels correlate with presence of vascular thrombosis; (G) Ang-2 levels correlate with presence of distant metastasis; (H) Ang-2 levels correlate with higher AFP levels. ${ }^{*} p<.05,{ }^{* *} p<.001$. 
score, and higher chance of metastasis. In agreement with our findings, the above-mentioned biomarker analysis of the SHARP trial identified correlation between circulating Ang-2 levels and the presence of macrovascular invasion and higher AFP levels [14]. Also consistent with our findings, Dias-Sanchez et al. [31] demonstrated that serum Ang-2 levels in $32 \mathrm{HCC}$ patients correlated with vascular invasion and thrombosis, AFP levels, and advanced BCLC staging.

Two additional interesting elements should be considered with regard to the role of Ang-2 as a noninvasive biomarker for HCC. First, therapies blocking Ang-2 are currently under development (Table 2) [32-45]. Second, the role of Ang-2 as a noninvasive biomarker in HCC might expand with incorporation of immunotherapy in the therapeutic arsenal for HCC [13]. Previous studies have suggested that Ang-2 may contribute to resistance mechanisms to immune checkpoint therapy by enhancing tumor recruitment of monocytes and macrophages and by upregulating PD-L1 expression in tumor-associated macrophages [26]. Recent data also demonstrated that concurrent neutralization of VEGFA and Ang-2 promotes the development and deployment of antitumor immunity in mouse models of cancer, expanding the rationale for trials combining Ang-2-directed therapy with checkpoint inhibitors [46]. This is very relevant to the current paradigm shift in systemic therapy options for HCC which has led to approval of nivolamb recently in HCC.

To the best of our knowledge, our current study provides the first report of the correlation of plasma Ang-1 levels with clinicopathologic and prognostic features in HCC. Ang-1 expression quantified by mRNA was shown to correlate with tumor vascularity in previous reports [24]. In addition, circulating levels of Ang-1 have demonstrated prognostic correlation in other cancers, such as cervical, peritoneal mesothelioma, and nasopharynx and larynx carcinomas [47-49].

Therefore, taken together, our results indicate that circulating Ang-1 and Ang-2 levels correlate both with the presence of cirrhosis and with advanced HCC clinicopathologic features, suggesting also a role in tumor progression. These findings complement results from previous studies. First, previous data has demonstrated that Ang-1 secreted by hepatic stellate cells contributes to liver fibrosis, and circulating Ang-1 and Ang-2 levels have been described as non-invasive biomarkers of cirrhosis in patients with chronic hepatitis $\mathrm{C}$ infection, highlighting the close relationship between angiogenesis and liver fibrosis $[31,50]$. Second, targeting Tie-2, the receptor for Ang-1 and Ang-2, promote microvascular stability and decrease angiogenesis, and a selective Ang-2 inhibitor has been shown to reduce vascular growth by $46 \%$ and tumor size by $62 \%$ over a period of 26 days in preclinical models, demonstrating the role of this signaling pathway in HCC progression and further establishing angiopoietin as a potential target for therapy development (Table 2) [51].

In summary, we have demonstrated that circulating levels of the proangiogenic cytokines Ang-1 and Ang-2 could be promising noninvasive prognostic and diagnostic markers in HCC. Independent validation studies with serial plasma measurements are needed to further characterize the significance of plasma angiopoietins levels, not only as
$\mathbf{A}$

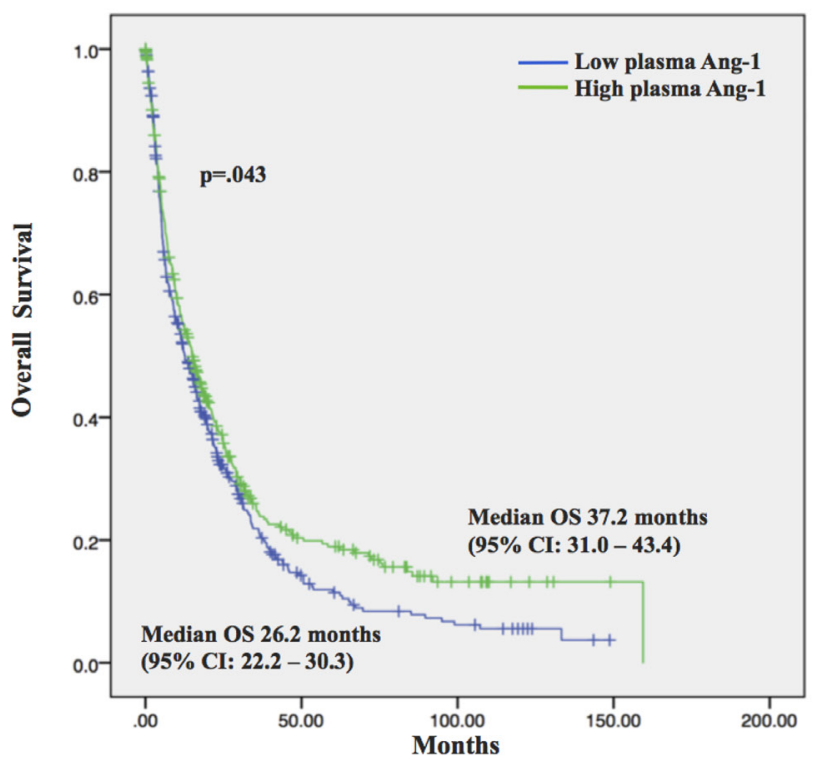

B

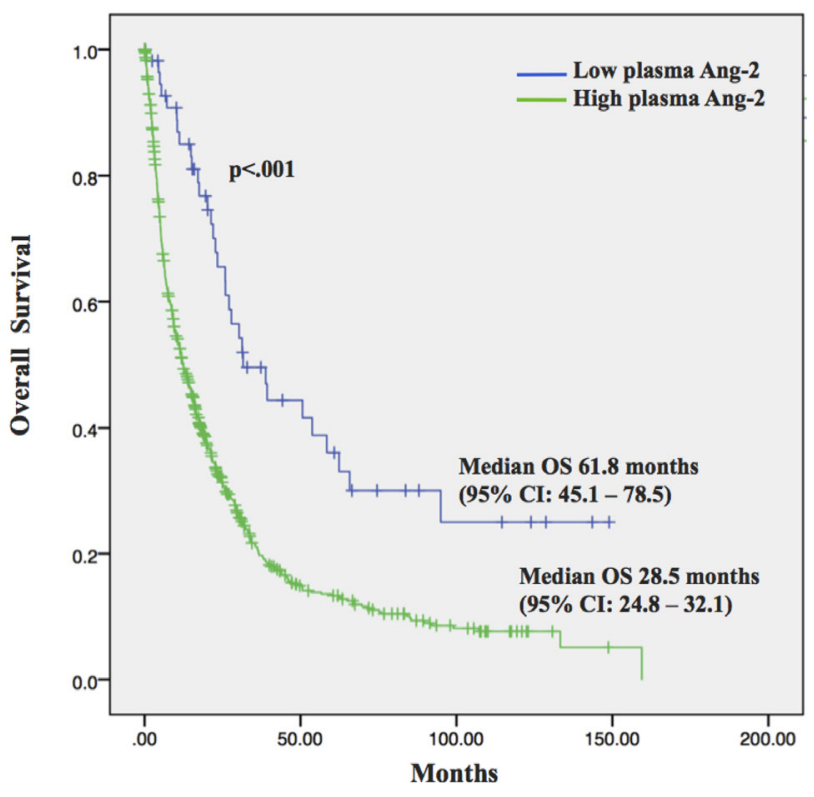

Figure 3: Overall survival (OS) and the 95\% confidence interval (CI) in 767 HCC patients. (A) Patients with high plasma Ang-1 had significantly longer OS as compared to those with low plasma Ang-1; (B) Patients with low plasma Ang-2 had significantly longer OS as compared to those with low plasma Ang-2. 
Table 2: Ang-2-targeted therapies in clinical development for cancer therapy (available at http://www.clinicaltrials. gov, accessed July 2018)

\begin{tabular}{|c|c|c|c|}
\hline Drug name & Description & List of clinical trials & Status \\
\hline \multirow[t]{2}{*}{ MEDI3617 } & $\begin{array}{l}\text { Fully humanized IgG1k } \\
\text { mAb that binds to } \\
\text { human Ang-2 }\end{array}$ & $\begin{array}{l}\text { Phase I Trial of Tremelimumab Plus MEDI3617 in } \\
\text { Patients With Unresectable Stage III / IV Melanoma }\end{array}$ & Active, not recruiting \\
\hline & & $\begin{array}{c}\text { Phase } 1 / 1 b \text {, Open-Label, Dose-Escalation and } \\
\text { Expansion Study to Evaluate the Safety and Antitumor } \\
\text { Activity of MED3617 as Single-Agent or in } \\
\text { Combination in Adult Subjects With Advanced Solid } \\
\text { Tumors }\end{array}$ & Completed, with results [25] \\
\hline \multirow[t]{12}{*}{$\begin{array}{l}\text { Trebananib } \\
\text { (AMG386) }\end{array}$} & $\begin{array}{l}\text { Fc-fusion peptibody that } \\
\text { prevents Tie } 2 \text { receptor } \\
\text { activation through } \\
\text { binding of both Ang-1 } \\
\text { and Ang-2 }\end{array}$ & $\begin{array}{l}\text { Phase } 2 \text { study of trebananib with and without } \\
\text { bevacizumab for patients with recurrent glioblastoma }\end{array}$ & Completed, with results [26] \\
\hline & & $\begin{array}{c}\text { Phase I Trial Study of Trebananib in Relapsed Solid } \\
\text { Tumors, Including Primary Tumors of the Central } \\
\text { Nervous System ADVL1115: A Children's Oncology } \\
\text { Group Phase I Consortium Report }\end{array}$ & Completed, with results [27] \\
\hline & & $\begin{array}{c}\text { Phase II Study of First-Line Trebananib Plus } \\
\text { Sorafenib in Patients with Advanced Hepatocellular } \\
\text { Carcinoma }\end{array}$ & Completed, with results [28] \\
\hline & & $\begin{array}{c}\text { ENGOT-ov-6/TRINOVA-2: Randomised, double- } \\
\text { blind, phase } 3 \text { study of pegylated liposomal } \\
\text { doxorubicin plus trebananib or placebo in women } \\
\text { with recurrent partially platinum-sensitive or resistant } \\
\text { ovarian cancer }\end{array}$ & Completed, with results [29] \\
\hline & & $\begin{array}{c}\text { Final results of a phase } 3 \text { study of trebananib plus } \\
\text { weekly paclitaxel in recurrent ovarian cancer } \\
\text { (TRINOVA-1): Long-term survival, impact of ascites, } \\
\text { and progression-free survival-2 }\end{array}$ & Completed, with results [30] \\
\hline & & $\begin{array}{c}\text { Trebananib (AMG 386) in Combination With } \\
\text { Sunitinib in Patients With Metastatic Renal Cell } \\
\text { Cancer: An Open-Label, Multicenter, Phase II Study }\end{array}$ & Completed, with results [31] \\
\hline & & $\begin{array}{c}\text { Phase II trial of Trebananib (AMG 386) in } \\
\text { patients with persistent/recurrent carcinoma of the } \\
\text { endometrium }\end{array}$ & Completed, with results [32] \\
\hline & & $\begin{array}{l}\text { Pharmacokinetic drug-drug interaction study of the } \\
\text { angiopoietin-1/angiopoietin-2-inhibiting peptibody } \\
\text { trebananib (AMG 386) and paclitaxel in patients with } \\
\text { advanced solid tumors }\end{array}$ & Completed, with results [33] \\
\hline & & $\begin{array}{l}\text { Trebananib (AMG 386) plus weekly paclitaxel with or } \\
\text { without bevacizumab as first-line therapy for HER2- } \\
\text { negative locally recurrent or metastatic breast cancer: } \\
\text { A phase } 2 \text { randomized study }\end{array}$ & Completed, with results [34] \\
\hline & & $\begin{array}{l}\text { A phase } 1 \mathrm{~b} \text {, open-label study of trebananib plus } \\
\text { bevacizumab or motesanib in patients with solid } \\
\text { tumours. }\end{array}$ & Completed, with results [35] \\
\hline & & $\begin{array}{l}\text { Phase II study of the angiopoietin } 1 \text { and } 2 \text { peptibody } \\
\text { trebananib for the treatment of angiosarcoma. }\end{array}$ & Completed, with results [36] \\
\hline & & $\begin{array}{c}\text { A Phase lb Study of the Safety, Feasibility, and } \\
\text { Pharmacokinetics of AMG386 Alone and in } \\
\text { Combination With Low Dose Cytarabine in Acute } \\
\text { Myeloid Leukemia (AML) Patients }\end{array}$ & Completed, no results \\
\hline
\end{tabular}


Phase Ib Study to Test the Safety and Potential

Synergy of Pembrolizumab (Anti-PD-1) and

AMG386(Angiopoietin-2 (Ang-2) in Patients With Advanced Solid Tumor

I-SPY 2 TRIAL: Neoadjuvant and Personalized Adaptive Novel Agents to Treat Breast Cancer (I-SPY 2)
A Phase I First-in-Human Study of Nesvacumab (REGN910), a Fully Human Anti-Angiopoietin-2

(Ang2) Monoclonal Antibody, in Patients with Advanced Solid Tumors.

A Phase 1b Study of Combined Angiogenesis Inhibition by Administering REGN910 and Aflibercept (Ziv-aflibercept) in Patients With Advanced Solid Malignancies

\begin{tabular}{lc}
\hline Vanucizumab & Bispecific mAb \\
(RG7221) & targeting VEGF-A and \\
Ang-2
\end{tabular}

First-in-Human Phase I Study of Single-agent

Vanucizumabin Adult Patients with Advanced Solid Tumors

An Open-label, Multi-center, Dose Escalation Phase I Study of Single Agent RO5520985 (Vanucizumab), and in Combination With Atezolizumab, Administered as an Intravenous Infusion in Patients With Locally Advanced or Metastatic Solid Tumors

A Phase II, Multicenter, Randomized, DoubleBlind Study to Evaluate the Efficacy and Safety of RO5520985 (Vanucizumab) Plus FOLFOX Versus

Bevacizumab Plus FOLFOX in Patients With Previously Untreated Metastatic Colorectal Cancer

An Open-Label, Multicenter, Dose Escalation Phase Ib Study With Expansion Cohorts to Evaluate the Safety, Pharmacokinetics, Pharmacodynamics, and Therapeutic Activity of RO7009789 in Combination With Vanucizumab in Patients With Metastatic Solid Tumors

\begin{tabular}{cc}
\hline LY3127804 & Humanized lgG4 \\
isotype mAB that \\
selectively binds to \\
Ang-2
\end{tabular}

A Phase 1 Study of LY3127804 as Monotherapy and in Combination With Ramucirumab in Patients With Advanced Solid Tumors

Active, recruiting

Active, recruiting

Completed, with results [37]

Completed, no results Completed, with results [38]

Completed, no results

Completed, no results

Active, recruiting

Active, not recruiting

prognostic markers, but even more critical, as predictors of response or resistance to therapies, particularly in the era of immunotherapy and antiangiogenesis-directed HCC therapy.

\section{MATERIALS AND METHODS}

\section{Patients and specimens}

The current analysis is part of a case-control, hospital-based study approved by the Institutional Review Board (IRB) of The University of Texas MD Anderson Cancer Center. We obtained written informed consent from all study subjects. With IRB approval, we prospectively collected clinicopathologic data and plasma samples from 767 patients treated at MD Anderson Cancer Center between 2001 and 2014. All patients were treatment-naïve. We have recorded the following characteristics from patients' medical records, at the time of blood collection: demographic parameters, HCC risk factors (such as cirrhosis, alcohol consumption, and hepatitis B or C infection), HCC treatment modalities received, survival data, and tumor variables such as number of liver nodules, size of each individual tumor, tumor grade and differentiation, the presence of macrovascular invasion, extrahepatic metastasis, and the percentage of tumor-occupied liver area. Information regarding disease staging was also collected with use of three recognized HCC classification systems: (1) the Barcelona Clinic Liver Cancer (BCLC), (2) the Cancer of the Liver Italian Program (CLIP), and (3) the AJCC tumor-node-metastasis (TNM) system.

There were two accepted means for the diagnosis of HCC: by biopsy and pathologic examination or by typical characteristics on contrast-enhanced cross-sectional imaging in cirrhotic patients (computed tomography or magnetic resonance imaging). Patients were included 
regardless of comorbid conditions. Cirrhotic patient controls consisted of 75 patients who were selected to represent patients in various stages of cirrhosis and ChildPugh scores, with multiple causes of underlying liver damage. Controls were healthy volunteers $(n=200)$ with no apparent laboratory or imaging evidence of liver damage.

\section{Measurement of plasma Ang-1 and Ang-2}

Ang-1 and Ang-2 plasma levels were measured in plasma samples with use of a commercially available multiplex immunoassay (Myriad, Human Discovery MAP, v3.3, Austin, TX, USA). All samples were collected prior to first cancer-directed treatment. There was no collection of samples after treatment, and no patient had a second measurement of circulation angiopoietin level at another time-point.

\section{Statistical analysis}

Statistical analyses were performed with use of Stata software (Stata Corp, College Station, TX, USA), and univariate analyses for categorical variables were performed by using the $\mathrm{X}^{2}$ or Fisher exact test. An analysis of variance (ANOVA) comparison test was utilized to determine differences in serum biomarker levels between groups. The cutoff value for low versus high Ang-1 and Ang-2 levels was set at the median levels of each angiogenic factor in the control group. The Kaplan-Meier method was used to estimate OS and survival results were compared by using the log-rank test. We considered $p$ values of less than 0.05 as statistically significant.

\section{Author contributions}

All authors contributed significantly to the final manuscript. RCP participated in the study design and writing of the manuscript; $\mathrm{MMH}$ contributed to the statistical plan, statistical analysis, and writing; RAW and YIA contributed to review of the clinical characteristics of patients and to the study design; LMG, DL, PC, KP, JM, RAW, AR, HA and AOK contributed to design of the study, statistical plan and to the writing of the final manuscript.

\section{CONFLICTS OF INTEREST}

The authors have no conflicts of interest to disclose.

\section{FUNDING}

Supported by National Institutes of Health R03 grants ES11481 (to MMH) and CA-106458 (to MMH), as well as R21 CA190945-01A1 (to AOK), and R21 CA170035-01 (to AOK).

\section{REFERENCES}

1. Ferlay J, Soerjomataram I, Dikshit R, Eser S, Mathers C, Rebelo M, Parkin DM, Forman D, Bray F. Cancer incidence and mortality worldwide: sources, methods and major patterns in GLOBOCAN 2012. Int J Cancer. 2015; 136:E359-86. https://doi.org/10.1002/ijc.29210.

2. Tannus RK, Almeida-Carvalho SR, Loureiro-Matos CA, Miziara-Gonzalez A, Salzedas-Netto AA, Szejnfeld D, D'Ippolito G, Pereira-Lanzoni V, Souza-Silva I. Evaluation of survival of patients with hepatocellular carcinoma: A comparative analysis of prognostic systems. PLoS One. 2018; 13:e0194922. https://doi.org/10.1371/journal. pone. 0194922 .

3. El-Serag HB, Rudolph KL. Hepatocellular carcinoma: epidemiology and molecular carcinogenesis. Gastroenterology. 2007; 132:2557-76. https://doi. org/10.1053/j.gastro.2007.04.061.

4. Singal AG, Nehra M, Adams-Huet B, Yopp AC, Tiro JA, Marrero JA, Lok AS, Lee WM. Detection of hepatocellular carcinoma at advanced stages among patients in the HALT-C trial: where did surveillance fail? Am J Gastroenterol. 2013; 108:425-32. https://doi.org/10.1038/ ajg.2012.449.

5. Wallace MC, Preen D, Jeffrey GP, Adams LA. The evolving epidemiology of hepatocellular carcinoma: a global perspective. Expert Rev Gastroenterol Hepatol. 2015; 9:765-79. https://doi.org/10.1586/17474124.2015.1028363.

6. Tandon P, Garcia-Tsao G. Prognostic indicators in hepatocellular carcinoma: a systematic review of 72 studies. Liver Int. 2009; 29:502-10. https://doi. org/10.1111/j.1478-3231.2008.01957.x.

7. Forner A, Reig M, Bruix J. Hepatocellular carcinoma. Lancet. 2018; 391:1301-14. https://doi.org/10.1016/ S0140-6736(18)30010-2.

8. Degasperi E, Colombo M. Distinctive features of hepatocellular carcinoma in non-alcoholic fatty liver disease. Lancet Gastroenterol Hepatol. 2016; 1:156-64. https://doi.org/10.1016/S2468-1253(16)30018-8.

9. Yin Z, Jin H, Ma T, Zhou Y, Yu M, Jian Z. A metaanalysis of long-term survival outcomes between surgical resection and radiofrequency ablation in patients with single hepatocellular carcinoma $\leq 2 \mathrm{~cm}$ (BCLC very early stage). Int J Surg. 2018; 56:61-67. https://doi.org/10.1016/j. ijsu.2018.04.048.

10. Reig M, da Fonseca LG, Faivre S. New trials and results in systemic treatment of HCC. J Hepatol. 2018; 69:525-33. https://doi.org/10.1016/j.jhep.2018.03.028.

11. Bupathi M, Kaseb A, Janku F. Angiopoietin 2 as a therapeutic target in hepatocellular carcinoma treatment: current perspectives. Onco Targets Ther. 2014; 7:1927-32.

12. Llovet JM, Ricci S, Mazzaferro V, Hilgard P, Gane E, Blanc JF, de Oliveira AC, Santoro A, Raoul JL, Forner 
A, Schwartz M, Porta C, Zeuzem S, et al, and SHARP Investigators Study Group. Sorafenib in advanced hepatocellular carcinoma. N Engl J Med. 2008; 359:37890. https://doi.org/10.1056/NEJMoa0708857.

13. El-Khoueiry AB, Sangro B, Yau T, Crocenzi TS, Kudo M, Hsu C, Kim TY, Choo SP, Trojan J, Welling TH 3rd, Meyer T, Kang YK, Yeo W, et al. Nivolumab in patients with advanced hepatocellular carcinoma (CheckMate 040): an open-label, non-comparative, phase $1 / 2$ dose escalation and expansion trial. Lancet. 2017; 389:2492-502. https:// doi.org/10.1016/S0140-6736(17)31046-2.

14. Llovet JM, Peña CE, Lathia CD, Shan M, Meinhardt G, Bruix J, and SHARP Investigators Study Group. Plasma biomarkers as predictors of outcome in patients with advanced hepatocellular carcinoma. Clin Cancer Res. 2012; 18:2290-300. https://doi.org/10.1158/1078-0432. CCR-11-2175.

15. Chen L, Yang Z, Wang G, Wang C. Expression of angiopoietin-2 gene and its receptor Tie2 in hepatocellular carcinoma. J Tongji Med Univ. 2001; 21:228-30, 235.

16. Sharma BK, Srinivasan R, Kapil S, Singla B, Saini N, Chawla YK, Chakraborti A, Duseja A, Kalra N, Dhiman RK. Serum levels of angiogenic and anti-angiogenic factors: their prognostic relevance in locally advanced hepatocellular carcinoma. Mol Cell Biochem. 2013; 383:103-12. https://doi.org/10.1007/s11010-013-1759-7.

17. Tanaka S, Mori M, Sakamoto Y, Makuuchi M, Sugimachi $\mathrm{K}$, Wands JR. Biologic significance of angiopoietin-2 expression in human hepatocellular carcinoma. J Clin Invest. 1999; 103:341-45. https://doi.org/10.1172/JCI4891.

18. Moon WS, Rhyu KH, Kang MJ, Lee DG, Yu HC, Yeum JH, Koh GY, Tarnawski AS. Overexpression of VEGF and angiopoietin 2: a key to high vascularity of hepatocellular carcinoma? Mod Pathol. 2003; 16:552-57. https://doi. org/10.1097/01.MP.0000071841.17900.69.

19. Gerald D, Chintharlapalli S, Augustin HG, Benjamin LE. Angiopoietin-2: an attractive target for improved antiangiogenic tumor therapy. Cancer Res. 2013; 73:164957. https://doi.org/10.1158/0008-5472.CAN-12-4697.

20. Papapetropoulos A, García-Cardeña G, Dengler TJ, Maisonpierre PC, Yancopoulos GD, Sessa WC. Direct actions of angiopoietin-1 on human endothelium: evidence for network stabilization, cell survival, and interaction with other angiogenic growth factors. Lab Invest. 1999; 79:213-23.

21. Cascone T, Heymach JV. Targeting the angiopoietin/Tie2 pathway: cutting tumor vessels with a double-edged sword? J Clin Oncol. 2012; 30:441-44. https://doi.org/10.1200/ JCO.2011.38.7621.

22. Bupathi M, Kaseb A, Meric-Bernstam F, Naing A. Hepatocellular carcinoma: where there is unmet need. Mol Oncol. 2015; 9:1501-09. https://doi.org/10.1016/j. molonc.2015.06.005

23. Reiss Y, Droste J, Heil M, Tribulova S, Schmidt MH, Schaper W, Dumont DJ, Plate KH. Angiopoietin-2 impairs revascularization after limb ischemia. Circ Res. 2007; 101:88-96. https://doi.org/10.1161/ CIRCRESAHA.106.143594.

24. Torimura T, Ueno T, Kin M, Harada R, Taniguchi E, Nakamura T, Sakata R, Hashimoto O, Sakamoto M, Kumashiro R, Sata M, Nakashima O, Yano H, Kojiro M. Overexpression of angiopoietin-1 and angiopoietin-2 in hepatocellular carcinoma. J Hepatol. 2004; 40:799-807. https://doi.org/10.1016/j.jhep.2004.01.027.

25. Mazzieri R, Pucci F, Moi D, Zonari E, Ranghetti A, Berti A, Politi LS, Gentner B, Brown JL, Naldini L, De Palma M. Targeting the ANG2/TIE2 axis inhibits tumor growth and metastasis by impairing angiogenesis and disabling rebounds of proangiogenic myeloid cells. Cancer Cell. 2011; 19:512-26. https://doi.org/10.1016/j.ccr.2011.02.005.

26. Wu X, Giobbie-Hurder A, Liao X, Connelly C, Connolly EM, Li J, Manos MP, Lawrence D, McDermott D, Severgnini M, Zhou J, Gjini E, Lako A, et al. Angiopoietin-2 as a Biomarker and Target for Immune Checkpoint Therapy. Cancer Immunol Res. 2017; 5:17-28. https://doi. org/10.1158/2326-6066.CIR-16-0206.

27. Rivera LB, Bergers G. Intertwined regulation of angiogenesis and immunity by myeloid cells. Trends Immunol. 2015; 36:240-49. https://doi.org/10.1016/j. it.2015.02.005.

28. Kaseb AO, Garrett-Mayer E, Morris JS, Xiao L, Lin E, Onicescu G, Hassan MM, Hassabo HM, Iwasaki M, Deaton FL, Abbruzzese JL, Thomas MB. Efficacy of bevacizumab plus erlotinib for advanced hepatocellular carcinoma and predictors of outcome: final results of a phase II trial. Oncology. 2012; 82:67-74. https://doi. org/10.1159/000335963.

29. Hernández-Bartolomé Á, López-Rodríguez R, Borque MJ, González-Moreno L, Real-Martínez Y, García-Buey L, Moreno-Otero R, Sanz-Cameno P. Angiopoietin-2/ angiopoietin-1 as non-invasive biomarker of cirrhosis in chronic hepatitis C. World J Gastroenterol. 2016; 22:974451. https://doi.org/10.3748/wjg.v22.i44.9744.

30. Scholz A, Rehm VA, Rieke S, Derkow K, Schulz P, Neumann K, Koch I, Pascu M, Wiedenmann B, Berg T, Schott E. Angiopoietin-2 serum levels are elevated in patients with liver cirrhosis and hepatocellular carcinoma. Am J Gastroenterol. 2007; 102:2471-81. https://doi. org/10.1111/j.1572-0241.2007.01377.x.

31. Diaz-Sanchez A, Matilla A, Nuñez O, Lorente R, Fernandez A, Rincón D, Campos R, Bañares R, Clemente G. Serum angiopoietin-2 level as a predictor of tumor invasiveness in patients with hepatocellular carcinoma. Scand J Gastroenterol. 2013; 48:334-43. https://doi.org/10.3109/0 0365521.2012 .746391$.

32. Hyman DM, Rizvi N, Natale R, Armstrong DK, Birrer M, Recht L, Dotan E, Makker V, Kaley T, Kuruvilla D, Gribbin M, McDevitt J, Lai DW, Dar M. Phase I Study of MEDI3617, a Selective Angiopoietin-2 Inhibitor Alone and Combined with Carboplatin/Paclitaxel, Paclitaxel, or 
Bevacizumab for Advanced Solid Tumors. Clin Cancer Res. 2018; 24:2749-57. https://doi.org/10.1158/1078-0432. CCR-17-1775.

33. Reardon DA, Lassman AB, Schiff D, Yunus SA, Gerstner ER, Cloughesy TF, Lee EQ, Gaffey SC, Barrs J, Bruno J, Muzikansky A, Duda DG, Jain RK, Wen PY. Phase 2 and biomarker study of trebananib, an angiopoietin-blocking peptibody, with and without bevacizumab for patients with recurrent glioblastoma. Cancer. 2018; 124:1438-48. https:// doi.org/10.1002/cncr.31172.

34. Leary SE, Park JR, Reid JM, Ralya AT, Baruchel S, Wu B, Roberts TP, Liu X, Minard CG, Fox E, Weigel B, Blaney S. Pediatric Phase I Trial and Pharmacokinetic Study of Trebananib in Relapsed Solid Tumors, Including Primary Tumors of the Central Nervous System ADVL1115: A Children's Oncology Group Phase I Consortium Report. Clin Cancer Res. 2017; 23:6062-69. https://doi. org/10.1158/1078-0432.CCR-16-2882.

35. Abou-Alfa GK, Blanc JF, Miles S, Ganten T, Trojan J, Cebon J, Liem AK, Lipton L, Gupta C, Wu B, Bass M, Hollywood E, Ma J, et al. Phase II Study of First-Line Trebananib Plus Sorafenib in Patients with Advanced Hepatocellular Carcinoma. Oncologist. 2017; 22:780-e65. https://doi.org/10.1634/theoncologist.2017-0058.

36. Marth C, Vergote I, Scambia G, Oberaigner W, Clamp A, Berger R, Kurzeder C, Colombo N, Vuylsteke P, Lorusso D, Hall M, Renard V, Pignata S, et al. ENGOT-ov-6/ TRINOVA-2: Randomised, double-blind, phase 3 study of pegylated liposomal doxorubicin plus trebananib or placebo in women with recurrent partially platinum-sensitive or resistant ovarian cancer. Eur J Cancer. 2017; 70:111-21. https://doi.org/10.1016/j.ejca.2016.09.004.

37. Monk BJ, Poveda A, Vergote I, Raspagliesi F, Fujiwara K, Bae DS, Oaknin A, Ray-Coquard I, Provencher DM, Karlan BY, Lhommé C, Richardson G, Rincón DG, et al. Final results of a phase 3 study of trebananib plus weekly paclitaxel in recurrent ovarian cancer (TRINOVA-1): long-term survival, impact of ascites, and progression-free survival-2. Gynecol Oncol. 2016; 143:27-34. https://doi. org/10.1016/j.ygyno.2016.07.112.

38. Atkins MB, Gravis G, Drosik K, Demkow T, Tomczak P, Wong SS, Michaelson MD, Choueiri TK, Wu B, Navale L, Warner D, Ravaud A. Trebananib (AMG 386) in Combination With Sunitinib in Patients With Metastatic Renal Cell Cancer: An Open-Label, Multicenter, Phase II Study. J Clin Oncol. 2015; 33:3431-38. https://doi. org/10.1200/JCO.2014.60.6012.

39. Moore KN, Sill MW, Tenney ME, Darus CJ, Griffin D, Werner TL, Rose PG, Behrens R. A phase II trial of trebananib (AMG 386; IND\#111071), a selective angiopoietin $1 / 2$ neutralizing peptibody, in patients with persistent/recurrent carcinoma of the endometrium: An NRG/Gynecologic Oncology Group trial. Gynecol Oncol. 2015; 138:513-18. https://doi.org/10.1016/j. ygyno.2015.07.006.
40. Diamond JR, Wu B, Agarwal N, Bowles DW, Lam ET, Werner TL, Rasmussen E, Gamelin E, Soto F, Friberg G, Sun YN, Sharma S. Pharmacokinetic drug-drug interaction study of the angiopoietin-1/angiopoietin-2-inhibiting peptibody trebananib (AMG 386) and paclitaxel in patients with advanced solid tumors. Invest New Drugs. 2015; 33:691-99. https://doi.org/10.1007/s10637-015-0236-4.

41. Diéras V, Wildiers H, Jassem J, Dirix LY, Guastalla JP, Bono P, Hurvitz SA, Gonçalves A, Romieu G, Limentani SA, Jerusalem G, Lakshmaiah KC, Roché H, et al. Trebananib (AMG 386) plus weekly paclitaxel with or without bevacizumab as first-line therapy for HER2-negative locally recurrent or metastatic breast cancer: A phase 2 randomized study. Breast. 2015; 24:182-90. https://doi.org/10.1016/j. breast.2014.11.003.

42. Hong DS, Kurzrock R, Mulay M, Rasmussen E, Wu BM, Bass MB, Zhong ZD, Friberg G, Rosen LS. A phase 1b, open-label study of trebananib plus bevacizumab or motesanib in patients with solid tumours. Oncotarget. 2014; 5:11154-67. https://doi.org/10.18632/oncotarget.2568.

43. D' Angelo SP, Mahoney MR, Van Tine BA, Adkins DR, Perdekamp MT, Condy MM, Luke JJ, Hartley EW, Antonescu CR, Tap WD, Schwartz GK. Alliance A091103 a phase II study of the angiopoietin 1 and 2 peptibody trebananib for the treatment of angiosarcoma. Cancer Chemother Pharmacol. 2015; 75:629-38. https:/doi. org/10.1007/s00280-015-2689-8.

44. Papadopoulos KP, Kelley RK, Tolcher AW, Razak AR, Van Loon K, Patnaik A, Bedard PL, Alfaro AA, Beeram M, Adriaens L, Brownstein CM, Lowy I, Kostic A, et al. A Phase I First-in-Human Study of Nesvacumab (REGN910), a Fully Human Anti-Angiopoietin-2 (Ang2) Monoclonal Antibody, in Patients with Advanced Solid Tumors. Clin Cancer Res. 2016; 22:1348-55. https://doi. org/10.1158/1078-0432.CCR-15-1221.

45. Hidalgo M, Martinez-Garcia M, Le Tourneau C, Massard C, Garralda E, Boni V, Taus A, Albanell J, Sablin MP, Alt M, Bahleda R, Varga A, Boetsch C, et al. First-in-Human Phase I Study of Single-agent Vanucizumab, A First-in-Class Bispecific Anti-Angiopoietin-2/Anti-VEGF-A Antibody, in Adult Patients with Advanced Solid Tumors. Clin Cancer Res. 2018; 24:1536-45. https://doi.org/10.1158/1078-0432. CCR-17-1588.

46. Schmittnaegel M, Rigamonti N, Kadioglu E, Cassará A, Wyser Rmili C, Kiialainen A, Kienast Y, Mueller HJ, Ooi CH, Laoui D, De Palma M. Dual angiopoietin-2 and VEGFA inhibition elicits antitumor immunity that is enhanced by PD-1 checkpoint blockade. Sci Transl Med. 2017; 9:eaak9670. https://doi.org/10.1126/scitranslmed. aak9670.

47. Güveli ME, Duranyildiz D, Karadeniz A, Bilgin E, Serilmez M, Soydinc HO, Yasasever V. Circulating serum levels of angiopoietin-1 and angiopoietin-2 in nasopharynx and larynx carcinoma patients. Tumour Biol. 2016; 37:8979-83. https://doi.org/10.1007/s13277-015-4777-0. 
48. Yang P, Chen N, Yang D, Crane J, Yang S, Wang H, Dong R, Yi X, Xie L, Jing G, Cai J, Wang Z. The ratio of serum Angiopoietin-1 to Angiopoietin-2 in patients with cervical cancer is a valuable diagnostic and prognostic biomarker. PeerJ. 2017; 5:e3387. https://doi.org/10.7717/peerj.3387.

49. Mikami K, Tabata C, Tabata R, Nogi Y, Terada T, Honda M, Kamiya H, Nishizaki T, Nakano T. Clinical significance of serum angiopoietin-1 in malignant peritoneal mesothelioma. Cancer Invest. 2013; 31:511-15. https://doi.org/10.3109/07 357907.2013.830734.

50. Taura K, De Minicis S, Seki E, Hatano E, Iwaisako K, Osterreicher CH, Kodama Y, Miura K, Ikai I, Uemoto S,
Brenner DA. Hepatic stellate cells secrete angiopoietin 1 that induces angiogenesis in liver fibrosis. Gastroenterology. 2008; 135:1729-38. https://doi.org/10.1053/j. gastro.2008.07.065.

51. Hashizume H, Falcón BL, Kuroda T, Baluk P, Coxon A, Yu D, Bready JV, Oliner JD, McDonald DM. Complementary actions of inhibitors of angiopoietin-2 and VEGF on tumor angiogenesis and growth. Cancer Res. 2010; 70:2213-23. https://doi.org/10.1158/0008-5472.CAN-09-1977. 